\title{
Review Article \\ Potential Risk Factors for the Onset of Complex Regional Pain Syndrome Type 1: A Systematic Literature Review
}

\author{
Tracey Pons, ${ }^{1}$ Edward A. Shipton, ${ }^{1}$ Jonathan Williman, ${ }^{2}$ and Roger T. Mulder ${ }^{3}$ \\ ${ }^{1}$ Department of Anaesthesia, University of Otago, Christchurch, Corner of Riccarton and Hagley Avenues, \\ Christchurch 8042, New Zealand \\ ${ }^{2}$ Department of Population Health, University of Otago, Christchurch, Corner of Riccarton and Hagley Avenues, \\ Christchurch 8042, New Zealand \\ ${ }^{3}$ Department of Psychological Medicine, University of Otago, Christchurch, Corner of Riccarton and Hagley Avenues, \\ Christchurch 8042, New Zealand
}

Correspondence should be addressed to Edward A. Shipton; shiptonea@xtra.co.nz

Received 9 October 2014; Revised 21 December 2014; Accepted 22 December 2014

Academic Editor: Alex Macario

Copyright (C) 2015 Tracey Pons et al. This is an open access article distributed under the Creative Commons Attribution License, which permits unrestricted use, distribution, and reproduction in any medium, provided the original work is properly cited.

\begin{abstract}
Anaesthetists in the acute and chronic pain teams are often involved in treating Complex Regional Pain Syndromes. Current literature about the risk factors for the onset of Complex Regional Pain Syndrome Type 1 (CRPS 1) remains sparse. This syndrome has a low prevalence, a highly variable presentation, and no gold standard for diagnosis. In the research setting, the pathogenesis of the syndrome continues to be elusive. There is a growing body of literature that addresses efficacy of a wide range of interventions as well as the likely mechanisms that contribute to the onset of CRPS 1 . The objective for this systematic search of the literature focuses on determining the potential risk factors for the onset of CRPS 1. Eligible articles were analysed, dated 1996 to April 2014, and potential risk factors for the onset of CRPS 1 were identified from 10 prospective and 6 retrospective studies. Potential risk factors for the onset of CRPS 1 were found to include being female, particularly postmenopausal female, ankle dislocation or intraarticular fracture, immobilisation, and a report of higher than usual levels of pain in the early phases of trauma. It is not possible to draw definite conclusions as this evidence is heterogeneous and of mixed quality, relevance, and weighting strength against bias and has not been confirmed across multiple trials or in homogenous studies.
\end{abstract}

\section{Introduction}

There is a growing body of literature addressing a variety of disorders known as Complex Regional Pain Syndrome (CRPS). It is a condition that presents with a pain experience that is severe and disproportionate to the inciting event and is accompanied by highly variable signs and symptoms of inflammatory, sensory, autonomic, trophic, or motor features. Anaesthetists in the acute and chronic pain teams are often involved in treating Complex Regional Pain Syndromes. The onset of CRPS can follow injuries ranging from minor injuries to fracture(s), from lesions of the central nervous system, or from surgery [1-3]. Its prevalence is low, ranging from 5.46 to 26.2 per $100000[4,5]$. This low prevalence has led to difficulty in research where robust statistical analysis necessitates larger sample sizes $[6,7]$.
Furthermore, CRPS nomenclature continues to be debated and remains controversial [8-11]. Research had shown that this condition is not wholly a problem of the sympathetic nervous system. The old terms "reflex sympathetic dystrophy" and "causalgia" needed to be changed [12]. In 1994, the committee for taxonomy of the International Association for the Study of Pain (IASP) identified specific diagnostic criteria for this syndrome that were termed the IASP criteria. This IASP committee changed the name to Complex Regional Pain Syndrome or CRPS. The term CRPS Type 1 (CRPS 1) applies, if there is no nerve damage, or CRPS Type 11, if the nerve is physically and permanently damaged, and this nomenclature replaced the terms "reflex sympathetic dystrophy" and "causalgia," respectively [13]. Other diagnostic criteria developed were the Veldman [14] and Harden/Bruehl [15] criteria that 
continue to be used in clinical practice and research. The Harden/Bruehl criteria became known as "The Budapest Criteria" with minor modifications. Though published in an IASP-sanctioned book, the Harden/Bruehl criteria have not been officially endorsed by the IASP. The "Budapest Criteria" are used in clinical diagnosis. Here a report of at least one symptom in 3 or 4 categories (sensory, vasomotor, sudomotor/oedema, motor/trophic) with at least one sign at time of evaluation in 2 or more of the categories (sensory, vasomotor, sudomotor/oedema, motor/trophic) confirms a clinical CRPS diagnosis. There must be no other diagnosis that better explains the signs and symptoms. Budapest Clinical Criteria have retained sensitivity almost identical to the IASP criteria but with much improved specificity.

In the "Budapest Research Criteria," diagnostic decision rule is at least one symptom in all four symptom categories and at least one sign (observed at evaluation) in two or more sign categories. The intent of the Budapest Research Criteria was to maximize specificity (minimize false positives) at the expense of sensitivity. They have a high specificity but a low sensitivity $[16,17]$. This systematic review explores the literature since 1999. It therefore includes a level of variation for diagnostic criteria.

CRPS 1 is considered by most to be overdiagnosed [6, $18,19]$. There are a few, however, who still consider it underdiagnosed [20]. The precise pathophysiological mechanisms and predictive factors underlying CRPS 1 or subsets of CRPS 1 remain unknown $[6,21-23]$. A standard diagnostic test is unavailable and the absence of a gold standard makes the validation of diagnostic criteria difficult $[6,24,25]$. Effective treatment strategies (in both the research and clinical fields) have moderate evidence [26-29]. A variety of medical and physiotherapy interventions and a multidisciplinary approach to the management of CRPS 1 continue to be widely used $[23,30,31]$. These factors contribute to the difficulty in determining potential risk factors for CRPS 1 in a reliable and statistically valid way.

There has been no systematic review of risk factors which may contribute to the onset of CRPS 1 . This is the first systematic review to address factors posing as possible risk factors for the onset of CRPS 1. This paper selects from the current literature to systematically describe factors which expose a potential risk factor for a possible relationship to the onset of CRPS 1. This paper defines a risk factor as a factor contributing to a likely association of the onset of CRPS 1 . This association is not necessarily causal.

\section{Materials and Methods}

2.1. Study Selection. Key words for CRPS (such as diagnosis, epidemiology, aetiology, genetics, history, pathophysiology, rehabilitation, risks, fractures, osteoporosis, or predictors) were combined in searches of Web of Science and OVID Medline for articles dated 1996 to April 2014. All abstracts were screened. Inclusion criteria for data extraction were articles written in English with reference to risks or predictors associated with the onset of CRPS 1. Exclusion criteria included articles written in other languages or no mention of CRPS 1 risks for either onset or outcomes or prognosis. A
TABLE 1: Search terms for Web of Science CRPS 1 risks.

\begin{tabular}{lcc}
\hline Database & $\begin{array}{c}\text { Search statement (1996 to } \\
\text { April 2014) }\end{array}$ & Results \\
\hline Web of Science & CRPS and risks & 128 \\
\hline
\end{tabular}

TABLE 2: Search terms for OVID Medline(R) CRPS 1 risks.

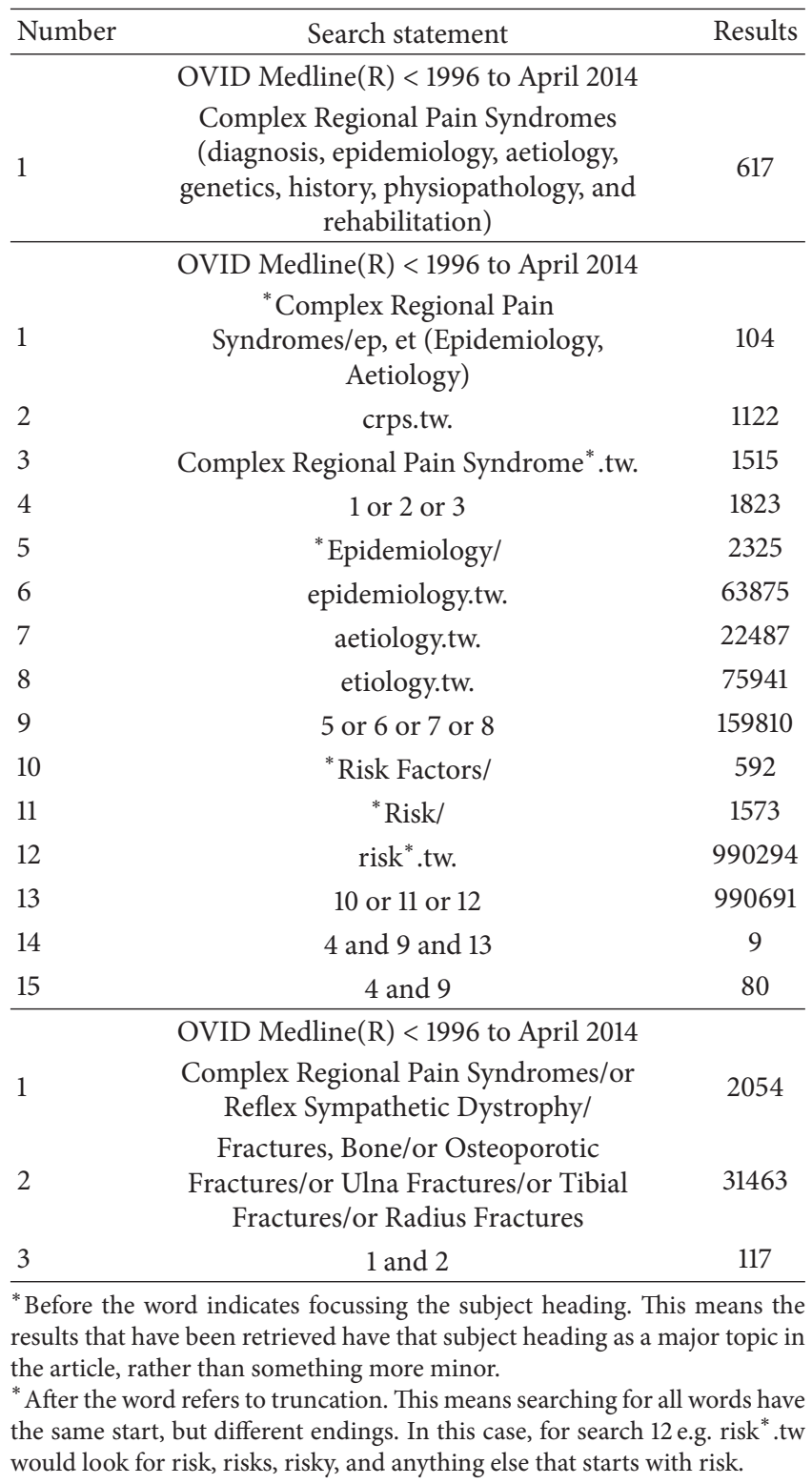

total of 969 abstracts were screened according to the study selection inclusion and exclusion criteria. Forty-one abstracts were included, and 928 abstracts were excluded. Search terms are outlined in Table 1 (Web of Science search) and Table 2 (Groups of OVID Medline searches).

2.2. Data Extraction. The methodology of the 41 articles included through the study selection was screened for data extraction with these inclusion criteria being randomised controlled trials, prospective and retrospective studies for 


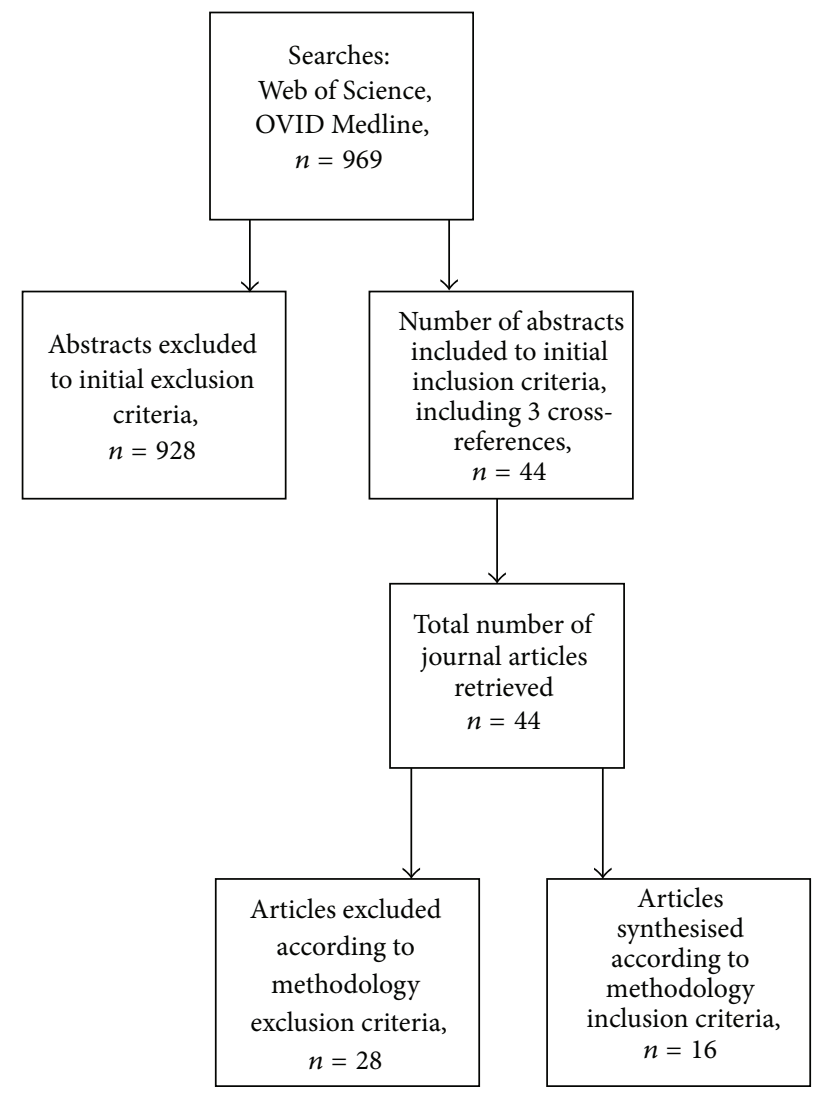

Figure 1: Summary of data extraction.

CRPS 1. Exclusion criteria incorporated CRPS Type 11, methodology used in animal studies, case studies, and case control studies or cross-sectional studies. Sixteen articles met these inclusion criteria (10 prospective studies, 6 retrospective studies). Twenty-five articles were excluded due to the direction of effect not being able to be determined. These inclusion and exclusion criteria were used to determine evidence for a direction of the effect specific for the likelihood or not for the potential risk for the onset of CRPS 1. A prospective or retrospective study can provide evidence for the likelihood (or not) of a risk towards the onset of a disease by determining a direction of effect. Animal studies, case studies, case control studies, and cross-sectional studies provide evidence of a relationship. They are not able to determine the direction of effect of this relationship over a period of time. Longitudinal, prospective, or retrospective studies by nature of their design are more able to determine this necessary direction of effect to reveal the potential risks for the onset of disease [7]. Figure 1 summarises the data extraction.

\section{Results}

3.1. Data Synthesis. No randomised controlled trials (RCTs) were found describing either possible risk or predictive factors for the onset of CRPS 1 . Ten prospective studies and six retrospective studies (total of 16) were included for the data synthesis. These data were synthesised from the following patient samples: 77 patients after knee replacement surgery; 1976 patients after distal fractures of the radius; 748 patients after wrist or ankle fractures; 168 CRPS male patients from the Turkish armed forces; 1639 CRPS 1 male and female patients with duration of disease for $<1$ year; and 453 male and female CRPS 1 patients with duration of disease $>1$ year. Four hundred and sixty patients were lost to follow-up; 21 eligible fracture patients were lost due to administrative errors; 216 patients refused to participate; there were 1052 controls (male and female). The human populations from which the patient epidemiological studies were sourced consisted of a total of 297,372 people. Eight studies used the IASP criteria for diagnosis. Six studies used a variation between the Veldman and Harden/Bruehl criteria. One study did not define their criteria stating their use of "standard criteria." Criteria were not stated at all in one study. In the prospective studies, follow-up time varied from 3 months to 2 years. In the retrospective studies, follow-up time varied from 3 to 10 years. Table 3 describes the data from the literature synthesised from prospective studies. Table 4 describes the data from the literature synthesised from retrospective studies.

3.2. Data Analysis. The data show a high level of heterogeneity. There are no particular variables consistent across these studies with evidence strong enough to comprise a risk factor. Rating criteria for quality and relevance and weighted strength against bias were based on published recommendations [7, 62, 63]. Quality and relevance criteria used included the following: the sample had to be representative of the CRPS 1 population; an adequate control group was needed; study attrition rate was required; adequate description of study and measurements used were necessary (to identify a potential risk factor); the statistical analysis needed to be appropriate.

The data were analysed for a weighted strength against the risk of possible bias. The criteria used included bias risk in sample selection, study design, funding provision, detection, and measurement. Two authors (Tracey Pons, Roger T. Mulder) independently assessed each paper for quality, relevance, and weighted strength against potential bias. Any disagreement was discussed and resolved by consensus. Where a disagreement could not be resolved by consensus, the two other authors (Edward A. Shipton, Jonathan Williman) arbitrated disagreement and facilitated consensus amongst all four authors. Observer expectancy was considered to be reduced since 2 authors' (Roger T. Mulder, Jonathan Williman) expertise is outside the pain management field; hence, no external observer was included as they were considered objective enough with no historical or current involvement with CRPS 1 diagnosis or management.

Quality and relevance were measured against six factors. Ratings were graded as poor, adequate, or good with the following algorithm: good = five or six factors rated as yes; adequate $=$ three or four factors rated as yes; and poor $=$ less than two factors rated as yes. The weighting against bias was measured against five factors. Ratings were graded as weak, acceptable, or strong with the following algorithm: strong = all five factors rated as no risk; acceptable = three or four factors rated as no risk; and weak = two or less factors rated as no risk. 


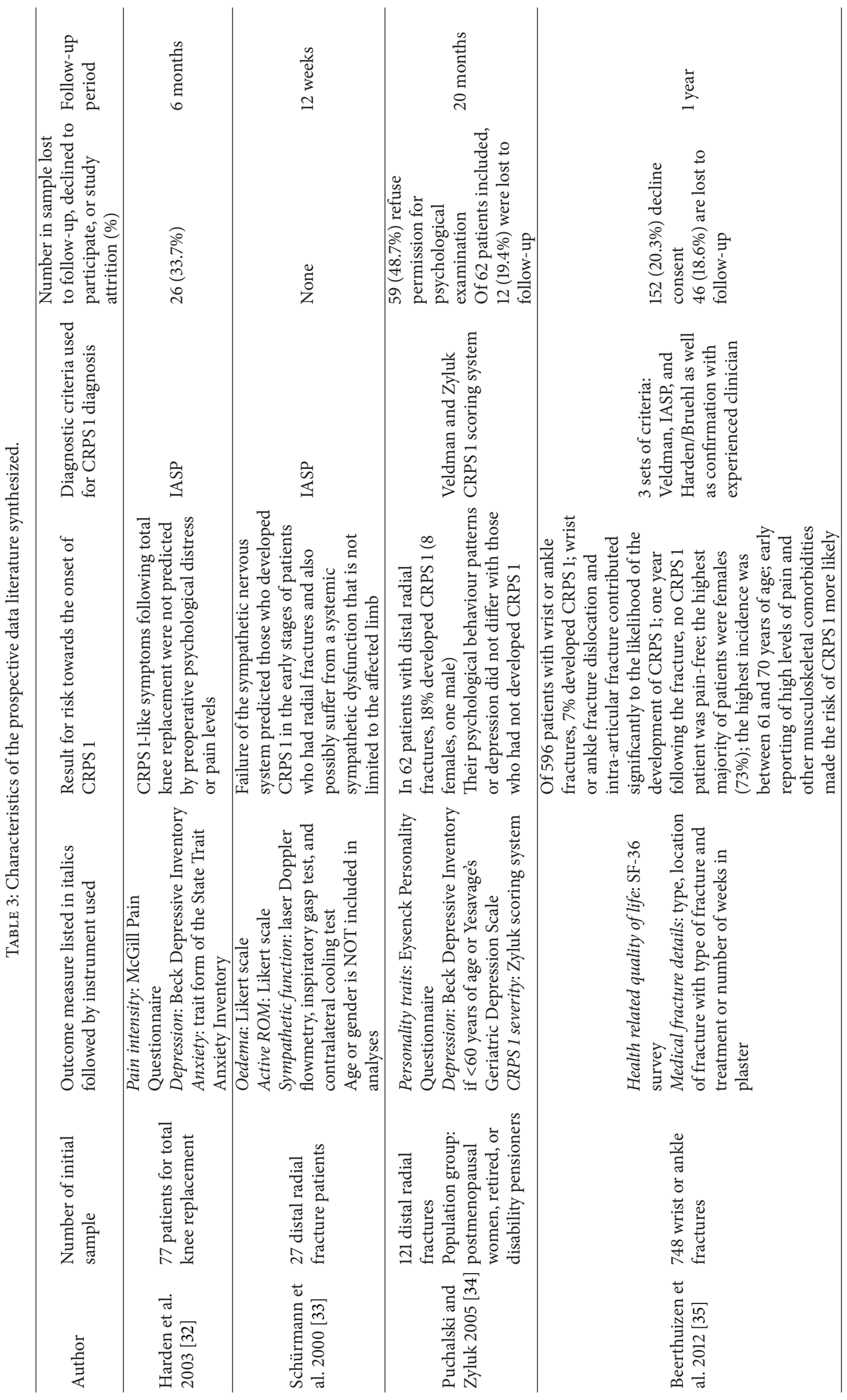




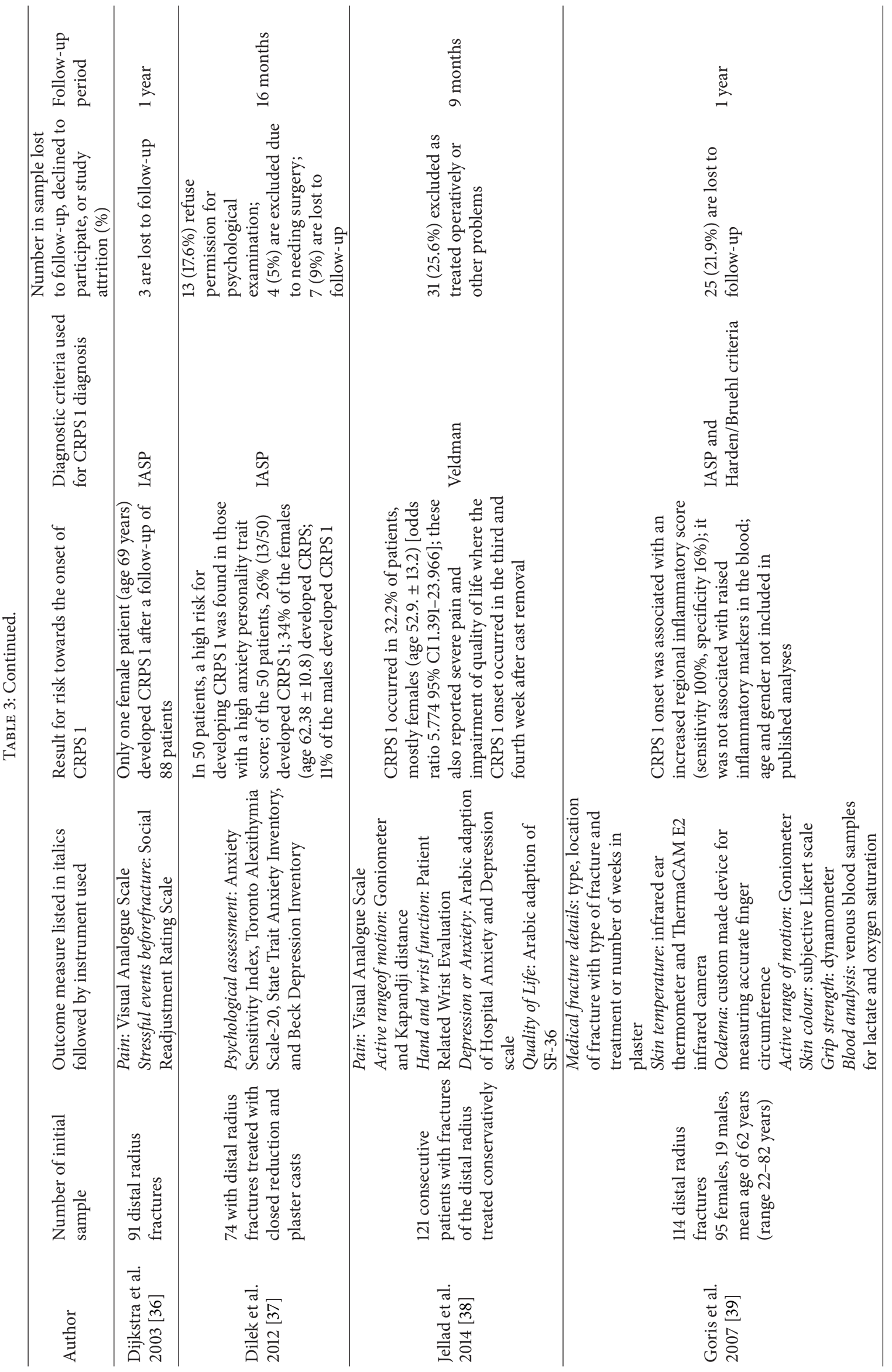




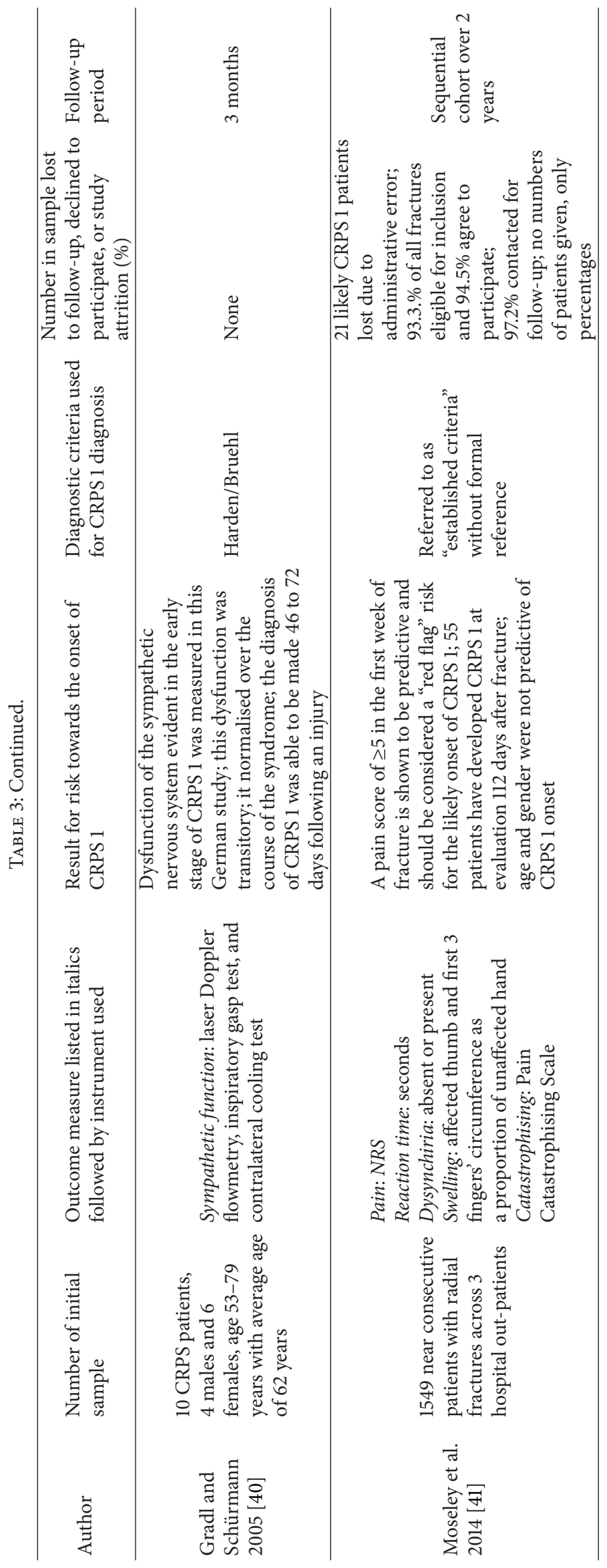




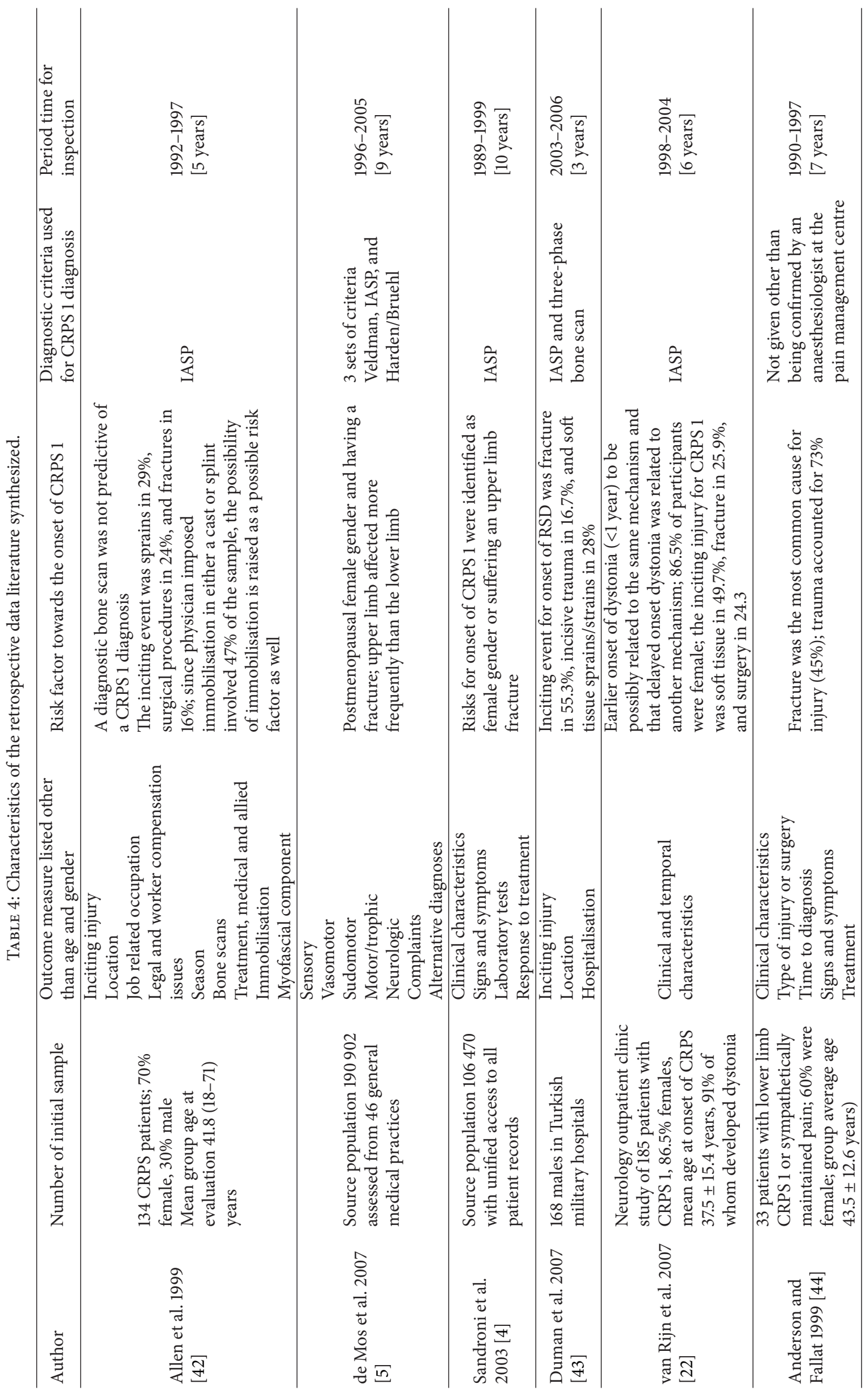


TABLE 5: Results presenting quality and relevance of data extraction for onset of CRPS 1 from prospective studies.

\begin{tabular}{|c|c|c|c|c|c|c|c|}
\hline Prospective studies & $\begin{array}{l}\text { Population sample } \\
\text { representative }\end{array}$ & $\begin{array}{c}\text { Adequate } \\
\text { control group }\end{array}$ & $\begin{array}{c}\text { Study } \\
\text { attrition } \\
\text { described }\end{array}$ & $\begin{array}{l}\text { Risk/predictor } \\
\text { outcome } \\
\text { adequately } \\
\text { defined }\end{array}$ & $\begin{array}{l}\text { Risk/predictor } \\
\text { outcome } \\
\text { adequately } \\
\text { measured }\end{array}$ & $\begin{array}{c}\text { Analysis } \\
\text { statistically } \\
\text { appropriate }\end{array}$ & Quality \\
\hline Harden et al. 2003 [32] & No & No & Yes & Yes & Yes & Yes & Adequate \\
\hline $\begin{array}{l}\text { Schürmann et al. } 2000 \\
\text { [33] }\end{array}$ & No & No & No & Yes & Yes & No & Poor \\
\hline $\begin{array}{l}\text { Puchalski and Zyluk. } \\
2005 \text { [34] }\end{array}$ & No & No & Yes & Partly & Yes & Yes & Poor \\
\hline $\begin{array}{l}\text { Beerthuizen et al. } 2012 \\
\text { [35] }\end{array}$ & Yes & Yes & Yes & Yes & Yes & Yes & Good \\
\hline $\begin{array}{l}\text { Dijkstra et al. } 2003 \\
{[36,46]}\end{array}$ & No & Yes & Yes & Partly & No & No & Poor \\
\hline Dilek et al. 2012 [37] & No & No & Yes & Yes & Yes & No & Adequate \\
\hline Jellad et al. 2014 [38] & No & Yes & Yes & Yes & No & Yes & Adequate \\
\hline Goris et al. 2007 [39] & No & Yes & Yes & Yes & Yes & Yes & Good \\
\hline $\begin{array}{l}\text { Gradl and Schürmann } \\
2005 \text { [40] }\end{array}$ & Partly & No & No & Yes & Yes & No & Poor \\
\hline Moseley et al. 2014 [41] & Yes & Yes & Partly & Yes & No & Yes & Adequate \\
\hline
\end{tabular}

TABLE 6: Results presenting quality and relevance of data extraction for onset of CRPS 1 from retrospective studies.

\begin{tabular}{|c|c|c|c|c|c|c|c|}
\hline Retrospective studies & $\begin{array}{l}\text { Population sample } \\
\text { representative }\end{array}$ & $\begin{array}{c}\text { Adequate } \\
\text { control group }\end{array}$ & $\begin{array}{c}\text { Study } \\
\text { attrition } \\
\text { described }\end{array}$ & $\begin{array}{l}\text { Risk/predictor } \\
\text { outcome } \\
\text { adequately } \\
\text { defined }\end{array}$ & $\begin{array}{l}\text { Risk/predictor } \\
\text { outcome } \\
\text { adequately } \\
\text { measured }\end{array}$ & $\begin{array}{c}\text { Analysis } \\
\text { statistically } \\
\text { appropriate }\end{array}$ & Quality \\
\hline Allen et al. 1999 [42] & No & No & No & Yes & Yes & Yes & Adequate \\
\hline de Mos et al. 2007 [5] & Yes & Yes & No & Yes & Yes & Yes & Good \\
\hline Sandroni et al. 2003 [4] & Yes & No & Yes & Yes & Yes & Yes & Good \\
\hline Duman et al. 2007 [43] & No & No & No & Yes & No & No & Poor \\
\hline van Rijn et al. 2007 [22] & Yes & No & No & Yes & Yes & Yes & Good \\
\hline $\begin{array}{l}\text { Anderson and Fallat } \\
1999[44]\end{array}$ & Yes & No & No & No & Yes & Yes & Poor \\
\hline
\end{tabular}

These data provide a broad and heterogeneous research platform towards probing for possible risk factors for the onset of CRPS 1. In this systematic review, 2 prospective studies and 3 retrospective studies were rated as good (total of 5). Four prospective studies and 1 retrospective study were rated as adequate (total of 5). Four prospective studies and 2 retrospective studies were rated as poor (total of 6). For the weighted strength against bias, 7 prospective studies were weak, 2 were acceptable, and 1 was strong. In the retrospective studies, 3 were weak, 2 were acceptable, and 1 was strong. In summary for the weighted strength against bias, 10 were weak, 4 were acceptable, and 2 were strong. However, these findings should be treated with caution as their statistical reliability and consistency have not been established across multiple or homogeneous studies.

The quality and relevance data are outlined in Table 5 for prospective studies and in Table 6 for retrospective studies. The weighting strength against bias data is illustrated in Table 7 for prospective studies and in Table 8 for retrospective studies.
The following are shown not to be risk factors for the onset of CRPS 1: namely, preoperative psychological distress; preoperative pain levels (with poor quality, poor relevance, and weak weighting against bias); psychological behaviour and depression (with adequate quality and relevance but with weak weighting against bias); and a diagnostic bone scan (with adequate quality and relevance but with weak weighting against bias). The factors not considered to be risk factors for the onset of CRPS 1 are summarised in Table 9.

The potential risk factors identified with a strong weighting against bias as well as good quality and relevance are being female (particularly postmenopausal), a fracture of the distal radius, and dislocation or an intra-articular fracture of the ankle. The factors presenting as possible risks for the onset of CRPS 1 are summarised in Table 10.

\section{Discussion}

Potential risk factors identified (strong weighting against bias, good quality, and relevance) across the 16 papers 


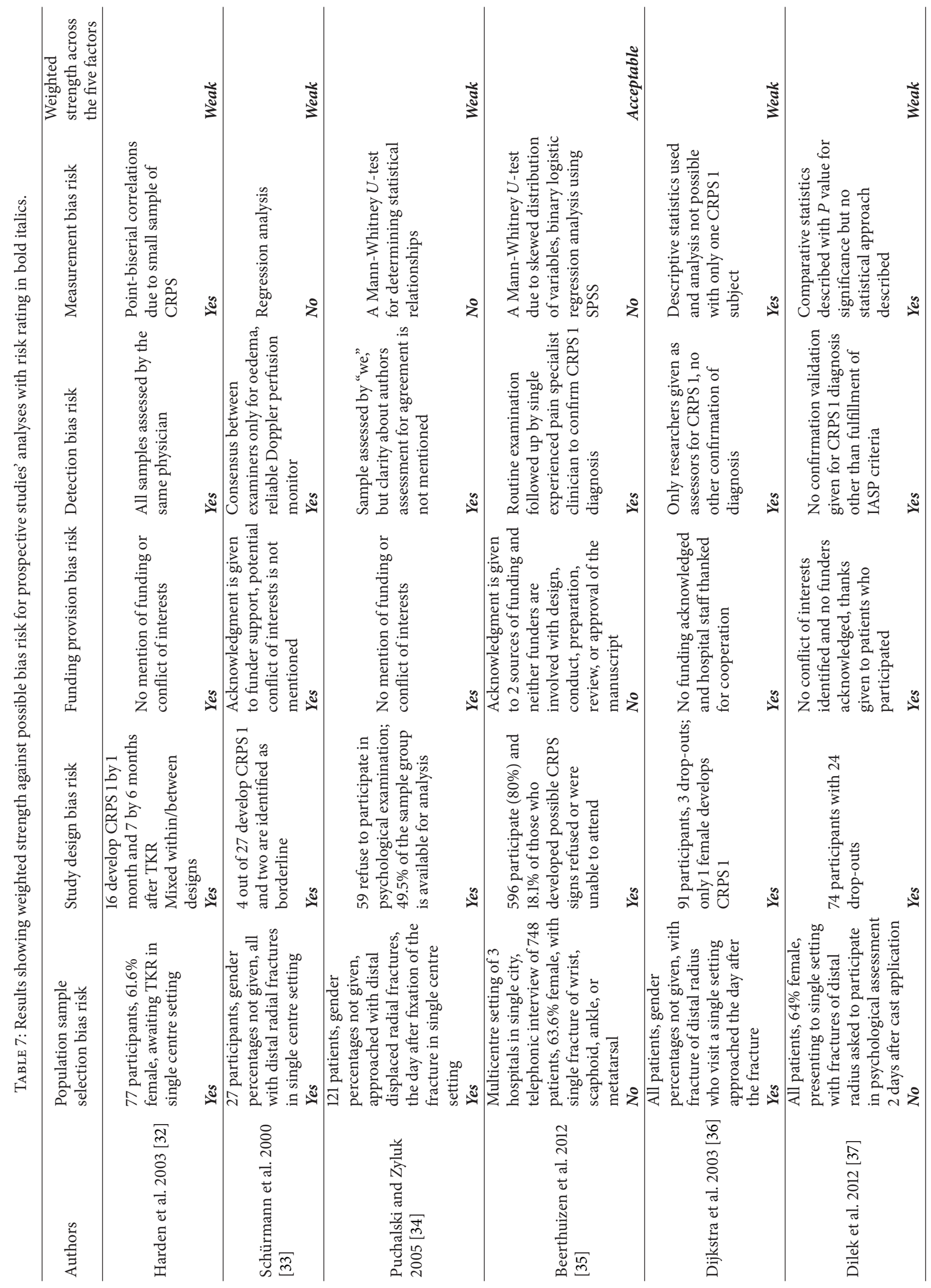




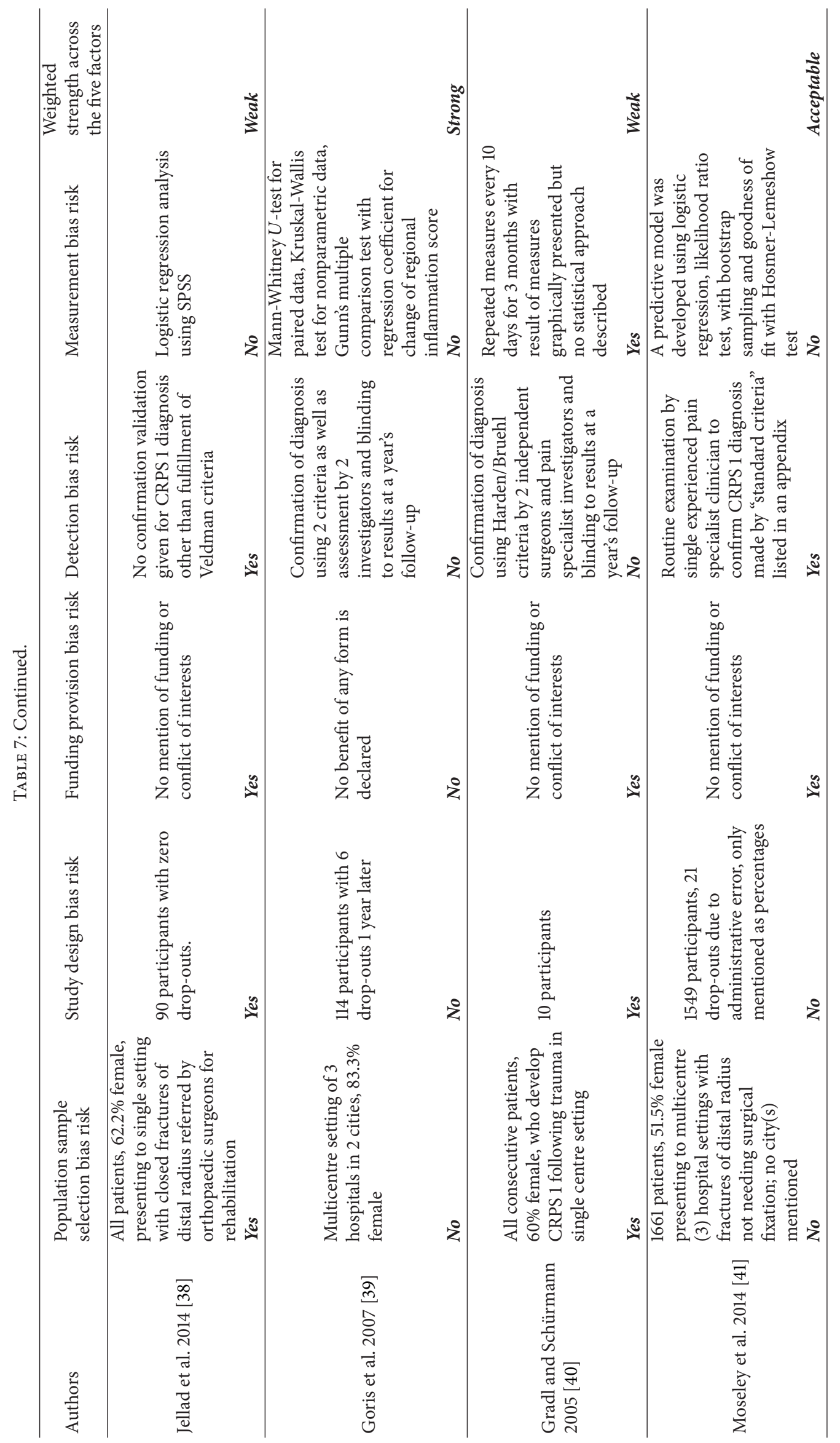




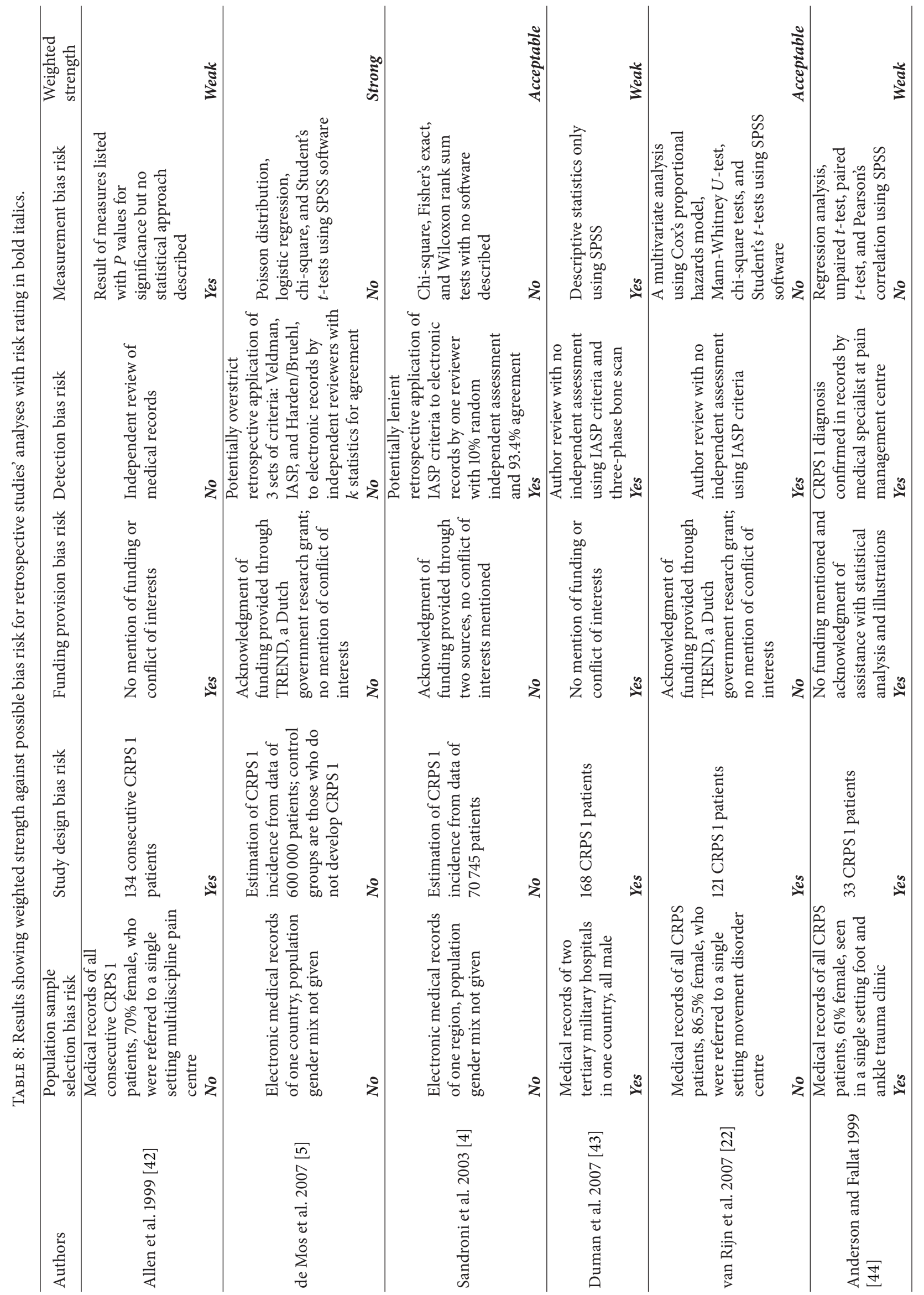


TABLE 9: Results summary showing factors examined and not found to be risk factors for the onset of CRPS 1 with weighting bias strength and quality and relevance.

\begin{tabular}{|c|c|c|c|}
\hline Not a risk factor for CRPS onset & Evidence source & Weighting bias strength & $\begin{array}{l}\text { Quality and relevance } \\
\text { of data extraction }\end{array}$ \\
\hline $\begin{array}{l}\text { Preoperative psychological distress or } \\
\text { pain levels }\end{array}$ & Puchalski and Zyluk 2005 [34] & Weak & Poor \\
\hline Diagnostic bone scan & Allen et al. 1999 [42] & Weak & Adequate \\
\hline Psychological behaviour: depression & Harden et al. 2003 [32] & Weak & Adequate \\
\hline
\end{tabular}

TABLE 10: Results summary showing possible risk factors for the onset of CRPS 1 with weighting bias strength and quality and relevance.

\begin{tabular}{|c|c|c|c|}
\hline Risk factors for CRPS onset & Evidence source & Weighting strength against bias & $\begin{array}{l}\text { Quality and relevance of } \\
\text { data extraction }\end{array}$ \\
\hline \multirow{6}{*}{ Female gender } & Puchalski and Zyluk 2005 [34] & Weak & Poor \\
\hline & Dijkstra et al. $2003[36,46]$ & Weak & Poor \\
\hline & Dilek et al. 2012 [37] & Weak & Adequate \\
\hline & Sandroni et al. 2003 [4] & Acceptable & Good \\
\hline & Allen et al. 1999 [42] & Weak & Adequate \\
\hline & van Rijn et al. 2007 [22] & Acceptable & Good \\
\hline \multirow{4}{*}{ Postmenopausal female gender } & Beerthuizen et al. 2012 [35] & Acceptable & Good \\
\hline & Jellad et al. 2014 [38] & Weak & Adequate \\
\hline & de Mos et al. 2007 [5] & Strong & Good \\
\hline & Sandroni et al. 2003 [4] & Acceptable & Good \\
\hline \multirow{5}{*}{$\begin{array}{l}\text { Fracture of distal radius or an } \\
\text { ankle dislocation or } \\
\text { intra-articular fracture }\end{array}$} & Beerthuizen et al. 2012 [35] & Acceptable & Good \\
\hline & Sandroni et al. $2003[4]$ & Acceptable & Good \\
\hline & de Mos et al. 2007 [5] & Strong & Good \\
\hline & Duman et al. 2007 [43] & Weak & Poor \\
\hline & Anderson and Fallat 1999 [44] & Weak & Poor \\
\hline Immobilisation & Allen et al. 1999 [42] & Weak & Adequate \\
\hline \multirow{3}{*}{$\begin{array}{l}\text { Report of higher than usual } \\
\text { levels of pain in } \\
\text { early phase of trauma }\end{array}$} & Beerthuizen et al. 2012 [35] & Acceptable & Good \\
\hline & Jellad et al. 2014 [38] & Weak & Adequate \\
\hline & Moseley et al. 2014 [41] & Acceptable & Adequate \\
\hline
\end{tabular}

are as follows: being female (particularly postmenopausal); obtaining a fracture of the distal radius; suffering an ankle dislocation or intra-articular fracture; and reports of higher than usual levels of pain in the early phases after trauma. The findings of this systematic review should be treated with caution as their statistical reliability and consistency have not yet been established across multiple or homogeneous studies and diagnostic criteria were mixed with Budapest Criteria not being used.

Age was accounted for in most studies. Age as a consistent potential risk factor for the onset of CRPS 1 could not be identified. This is shown in the population studies by Sandroni et al. [4], Moseley et al. [41], and de Mos et al. [5], as well as in the study by van Rijn et al. [22]. Although most of these data show that the risk increases in postmenopausal women $[5,34-38,40]$, the retrospective studies by Allen et al. [42] and by Anderson and Fallat [44] show a lower age. This might be due to average age of the group sample with the inclusion of both genders. The average age of the female sample groups is, unfortunately, not provided in either of these studies. Females at any age pose a higher risk for the onset of CRPS 1. However, the study of males in the armed forces by Duman et al. [43] shows that males are vulnerable as well. This systematic review shows that the onset of CRPS Type 1 is higher in females than in males in the mixed gender studies.

The data show the cause of the inciting event to be mixed. It can be related to surgery, fractures, or soft tissue injuries. The presence of other comorbidities is neither predictive nor a risk factor for the onset of CRPS 1 . Reports of higher than usual levels of pain in early phase of trauma were cited as strong evidence of a risk factor by Beerthuizen et al. [35] but as weak evidence by Jellad et al. [38].

Psychosocial factors are weakly weighted as a risk factor for the onset of CRPS 1. Moseley et al. find catastrophising not to be predictive for the onset of CRPS [41]. This is confirmed by other reviews and studies investigating psychological influences on the onset and progression of CRPS [58, 59, 6466]. Psychological behaviour, depression, and preoperative psychological distress or pain levels are not predictive of the onset of CRPS. The earlier literature described the "Sudeck A personality," a personality of high anxiety, as a likely risk 
factor towards the onset of CRPS 1 [61]. A high anxiety personality trait was identified by this systematic review as only a weak potential risk [37]. In other persistent pain conditions, these complex interactions between the onset of the pathogenesis of CRPS 1 and psychological factors are predictive of level of function $[45,60]$. Their interaction in CRPS 1 continues to be investigated by clinicians and researchers $[5,64]$.

These data show that a positive diagnostic bone scan is not a risk factor for the onset of CRPS 1 [46] and has been confirmed by other studies [42, 47, 48]. Interobserver consistency with interpretation of bone scans appears to be variable [49]. However, a diagnostic bone scan has been found to be helpful towards a diagnosis of CRPS 1 in some observations [50,51], but since recovery of bone mass following ankle fractures remains variable, it is not necessarily indicative of CRPS 1 [52].

Two recent systematic reviews have collated the prognostic findings about CRPS $1[53,67]$. Both agreed that the quality of evidence is poor. Our systematic review has confirmed this regarding the risks of onset of CRPS 1 . One review retrieved 1648 relevant papers of which twelve were robust enough for qualitative analysis [53]. Prognostic factors for poor outcomes were grouped within 7 clinical clusters as follows: (1) gender, where two studies show the male gender and one study shows the female gender; (2) age, where there is a high variation in age of onset affecting prognosis; (3) inciting event, such as polytrauma, inciting event other than fracture, severe initial injury, and distal articular location; (4) localisation site, either upper or lower extremity; (5) clinical features, such as exercised induced pain, sensory disturbances, initial cold skin temperature, complications of infection, skin ulcers, chronic oedema, dystonia or myoclonus, algodystrophy score $>7$ out to 10 , low SF-36 general health score, disease duration $>1$ year, and coexistence of misdiagnosed nerve injury and compression; (6) associated comorbidities included alcoholism and psychological background in nontraumatic CRPS 1; and (7) diagnosis where a delay of $>2$ months after inciting event was shown to be associated with poorer outcomes. The other review found that many CRPS 1 patients recover in 6-13 months but that a significant number continue to experience persistent pain and disability [67].

4.1. Implications for Research. This systematic review highlights potential risk factors that will contribute to future exploration about the onset of CRPS 1. Identifying risk factors associated with a poor prognosis is important as well. Risk factors for the onset of CRPS 1 identified in this systematic review may or may not be associated with a poor prognosis. The low prevalence of CRPS 1, its heterogeneous presentation, and its lack of highly specific or sensitive diagnostic criteria as well as the lack of clarity around consensus for these criteria create challenges in carrying out research $[4,6,21$, $42,54,55]$. In CRPS 1 , more trials across different settings are needed. The cross-sectional and case control studies excluded from this systematic review may still offer insight into the development of future longitudinal studies to determine direction and strength of the effects.
4.2. Implications for Clinical Practice. No specific or sensitive clinical sign or clinical symptom was shown in this review to pose a risk factor for the onset of CRPS 1. Clarity around the sensitivity and specificity of laboratory and imaging testing is needed [42, 47, 48, 51, 52]. This review confirms the importance of maintaining clinician awareness and of being aware of potential risk factors to enable the early diagnosis of CRPS 1 [56]. Evaluation by experienced clinicians hastens the diagnosis $[36,57]$. Early diagnosis and referral to pain management specialists and physiotherapists are related to better outcomes [53, 68, 69]. Moseley et al. [41] suggested that a pain score of $\geq 5$ in the first week of fracture could be considered a "red flag" risk for the likely onset of CRPS 1.

\section{Conclusion}

This systematic review shows that the accurate potential risk factors for the onset of CRPS 1 remain elusive. Studies remain heterogeneous, of mixed quality and relevance, and with varied weighting against the risks of bias. The low prevalence of CRPS 1 accompanied by a lack of a gold standard for diagnosis contributes to the difficulties around determining potential risk factors for the onset of CRPS 1.

Potential risk factors identified with strong weighting against bias and good quality and relevance are summarised as follows: being female (particularly postmenopausal); obtaining a fracture of the distal radius; suffering an ankle dislocation or intra-articular fracture; and reports of higher than usual levels of pain in the early phases after trauma. Potential risk factors with much weaker weighting against bias and poorer quality and relevance include immobilisation, psychosocial barriers, and a positive diagnostic bone scan. Definite conclusions cannot be drawn as evidence remains inconsistent across multiple trials or in homogenous studies.

\section{Conflict of Interests}

The authors declare no conflict of interests regarding the publication of this paper.

\section{References}

[1] M. de Mos, M. C. Sturkenboom, and F. J. Huygen, "Current understandings on complex regional pain syndrome," Pain Practice, vol. 9, no. 2, pp. 86-99, 2009.

[2] C. Maihöfner, F. Seifert, and K. Markovic, "Complex regional pain syndromes: new pathophysiological concepts and therapies," European Journal of Neurology, vol. 17, no. 5, pp. 649-660, 2010.

[3] S. Pertoldi and P. Di Benedetto, "Shoulder-hand syndrome after stroke. A complex regional pain syndrome," Europa Medicophysica, vol. 41, no. 4, pp. 283-292, 2005.

[4] P. Sandroni, L. M. Benrud-Larson, R. L. McClelland, and P. A. Low, "Complex regional pain syndrome type I: incidence and prevalence in Olmsted county, a population-based study," Pain, vol. 103, no. 1-2, pp. 199-207, 2003.

[5] M. de Mos, A. G. J. de Bruijn, F. J. P. M. Huygen, J. P. Dieleman, B. H. C. Stricker, and M. C. J. M. Sturkenboom, "The incidence 
of complex regional pain syndrome: a population-based study," Pain, vol. 129, no. 1-2, pp. 12-20, 2007.

[6] A. T. Borchers and M. E. Gershwin, "Complex regional pain syndrome: a comprehensive and critical review," Autoimmunity Reviews, vol. 13, no. 3, pp. 242-265, 2014.

[7] D. F. Stroup, J. A. Berlin, S. C. Morton et al., "Meta-analysis of observational studies in epidemiology: a proposal for reporting," Journal of the American Medical Association, vol. 283, no. 15, pp. 2008-2012, 2000.

[8] M. Stanton-Hicks, "Complex regional pain syndrome (type I, RSD; type II, causalgia): controversies," Clinical Journal of Pain, vol. 16, supplement, no. 2, pp. S33-S40, 2000.

[9] A. W. Burton, S. Bruehl, R. N. Harden et al., "Current diagnosis and therapy of complex regional pain syndrome: refining diagnostic criteria and therapeutic options," Expert Review of Neurotherapeutics, vol. 5, no. 5, pp. 643-651, 2005.

[10] T. J. Coderre, "Complex regional pain syndrome: what's in a name?" Journal of Pain, vol. 12, no. 1, pp. 2-12, 2011.

[11] M. Sumitani, M. Shibata, G. Sakaue, and T. Mashimo, "Development of comprehensive diagnostic criteria for complex regional pain syndrome in the Japanese population," Pain, vol. 150, no. 2, pp. 243-249, 2010.

[12] M. Stanton-Hicks, "Reflex sympathetic dystrophy: a sympathetically mediated pain syndrome or not?" Current Review of Pain, vol. 4, no. 4, pp. 268-275, 2000.

[13] S. Bruehl, R. N. Harden, B. S. Galer et al., "External validation of IASP diagnostic criteria for complex regional pain syndrome and proposed research diagnostic criteria," Pain, vol. 81, no. 1-2, pp. 147-154, 1999.

[14] P. H. J. M. Veldman, H. M. Reynen, I. E. Arntz, and R. J. A. Goris, "Signs and symptoms of reflex sympathetic dystrophy: prospective study of 829 patients," The Lancet, vol. 342, no. 8878, pp. 1012-1016, 1993.

[15] R. N. Harden, S. Bruehl, B. S. Galer et al., "Complex regional pain syndrome: are the IASP diagnostic criteria valid and sufficiently comprehensive?” Pain, vol. 83, no. 2, pp. 211-219, 1999.

[16] R. N. Harden, S. Bruehl, M. Stanton-Hicks, and P. R. Wilson, "Proposed new diagnostic criteria for complex regional pain syndrome," Pain Medicine, vol. 8, no. 4, pp. 326-331, 2007.

[17] R. N. Harden, S. Bruehl, R. S. G. M. Perez et al., "Validation of proposed diagnostic criteria (the 'Budapest Criteria') for Complex Regional Pain Syndrome,” Pain, vol. 150, no. 2, pp. 268-274, 2010.

[18] W. Jänig and R. Baron, "Complex regional pain syndrome: mystery explained?” Lancet Neurology, vol. 2, no. 11, pp. 687697, 2003.

[19] A. L. Oaklander and H. L. Fields, "Is reflex sympathetic dystrophy/complex regional pain syndrome type I a small-fiber neuropathy?" Annals of Neurology, vol. 65, no. 6, pp. 629-638, 2009.

[20] A. Quisel, J. M. Gill, and P. Witherell, "Complex regional pain syndrome underdiagnosed," Journal of Family Practice, vol. 54, no. 6, pp. 524-532, 2005.

[21] N. Harden, “The diagnosis of CRPS: are we there yet?" Pain, vol. 153, no. 6, pp. 1142-1143, 2012.

[22] M. A. van Rijn, J. Marinus, H. Putter, and J. J. van Hilten, "Onset and progression of dystonia in complex regional pain syndrome," Pain, vol. 130, no. 3, pp. 287-293, 2007.

[23] M. D. Stanton-Hicks, A. W. Burton, S. P. Bruehl et al., "An updated interdisciplinary clinical pathway for CRPS: report of an expert panel," Pain Practice, vol. 2, no. 1, pp. 1-16, 2002.
[24] F. Brunner, L. M. Bachmann, U. Weber et al., "Complex regional pain syndrome 1-the Swiss cohort study," BMC Musculoskeletal Disorders, vol. 9, article 92, 2008.

[25] D. Q. H. Tran, S. Duong, P. Bertini, and R. J. Finlayson, "Treatment of complex regional pain syndrome: a review of the evidence," Canadian Journal of Anesthesia, vol. 57, no. 2, pp. 149$166,2010$.

[26] W. S. Kingery, "A critical review of controlled clinical trials for peripheral neuropathic pain and complex regional pain syndromes," Pain, vol. 73, no. 2, pp. 123-139, 1997.

[27] R. S. Perez, G. Kwakkel, W. W. Zuurmond, and J. J. de Lange, "Treatment of reflex sympathetic dystrophy (CRPS Type 1): a research synthesis of 21 randomized clinical trials," Journal of Pain and Symptom Management, vol. 21, no. 6, pp. 511-526, 2001.

[28] T. Forouzanfar, A. J. A. Köke, M. van Kleef, and W. E. J. Weber, "Treatment of complex regional pain syndrome type I," European Journal of Pain, vol. 6, no. 2, pp. 105-122, 2002.

[29] W. H. Merritt, "The challenge to manage reflex sympathetic dystrophy/complex regional pain syndrome," Clinics in Plastic Surgery, vol. 32, no. 4, pp. 575-604, 2005.

[30] R. S. Perez, P. E. Zollinger, P. U. Dijkstra et al., "Evidence based guidelines for complex regional pain syndrome type 1 ," $B M C$ Neurology, vol. 10, article 20, 2010.

[31] F. van Eijs, M. Stanton-Hicks, J. van Zundert et al., "Evidencebased interventional pain medicine according to clinical diagnoses. 16. Complex regional pain syndrome," Pain Practice, vol. 11, no. 1, pp. 70-87, 2011.

[32] R. N. Harden, S. Bruehl, S. Stanos et al., "Prospective examination of pain-related and psychological predictors of CRPSlike phenomena following total knee arthroplasty: a preliminary study," Pain, vol. 106, no. 3, pp. 393-400, 2003.

[33] M. Schürmann, G. Gradl, J. Zaspel, M. Kayser, P. Löhr, and H.J. Andress, "Peripheral sympathetic function as a predictor of complex regional pain syndrome type I (CRPS I) in patients with radial fracture," Autonomic Neuroscience: Basic and Clinical, vol. 86, no. 1-2, pp. 127-134, 2000.

[34] P. Puchalski and A. Zyluk, "Complex regional pain syndrome type 1 after fractures of the distal radius: a prospective study of the role of psychological factors," Journal of Hand SurgeryBritish Volume, vol. 30, no. 6, pp. 574-580, 2005.

[35] A. Beerthuizen, D. L. Stronks, A. V. Spijker et al., "Demographic and medical parameters in the development of complex regional pain syndrome type 1 (CRPS1): prospective study on 596 patients with a fracture," Pain, vol. 153, no. 6, pp. 1187-1192, 2012.

[36] P. U. Dijkstra, J. W. Groothoff, H. J. Ten Duis, and J. H. B. Geertzen, "Incidence of complex regional pain syndrome type I after fractures of the distal radius," European Journal of Pain, vol. 7, no. 5, pp. 457-462, 2003.

[37] B. Dilek, B. Yemez, R. Kizil et al., "Anxious personality is a risk factor for developing complex regional pain syndrome type I," Rheumatology International, vol. 32, no. 4, pp. 915-920, 2012.

[38] A. Jellad, S. Salah, and Z. Ben Salah Frih, "Complex regional pain syndrome type I: incidence and risk factors in patients with fracture of the distal radius," Archives of Physical Medicine \& Rehabilitation, vol. 95, no. 3, pp. 487-492, 2014.

[39] R. J. A. Goris, M. Leixnering, W. Huber, M. Figl, M. Jaindl, and H. Redl, "Delayed recovery and late development of complex regional pain syndrome in patients with an isolated fracture of the distal radius: prediction of a regional inflammatory response by early signs," Journal of Bone and Joint SurgerySeries B, vol. 89, no. 8, pp. 1069-1076, 2007. 
[40] G. Gradl and M. Schürmann, "Sympathetic dysfunction as a temporary phenomenon in acute posttraumatic CRPS I," Clinical Autonomic Research, vol. 15, no. 1, pp. 29-34, 2005.

[41] G. L. Moseley, R. D. Herbert, T. Parsons, S. Lucas, J. J. van Hilten, and J. Marinus, "Intense pain soon after wrist fracture strongly predicts who will develop complex regional pain syndrome: prospective cohort study," Journal of Pain, vol. 15, no. 1, pp. 1623, 2014.

[42] G. Allen, B. S. Galer, and L. Schwartz, "Epidemiology of complex regional pain syndrome: a retrospective chart review of 134 patients," Pain, vol. 80, no. 3, pp. 539-544, 1999.

[43] I. Duman, U. Dincer, M. A. Taskaynatan, E. Cakar, I. Tugcu, and K. Dincer, "Reflex sympathetic dystrophy: a retrospective epidemiological study of 168 patients," Clinical Rheumatology, vol. 26, no. 9, pp. 1433-1437, 2007.

[44] D. J. Anderson and L. M. Fallat, "Complex regional pain syndrome of the lower extremity: a retrospective study of 33 patients," Journal of Foot \& Ankle Surgery, vol. 38, no. 6, pp. 381387, 1999.

[45] C. E. Dionne, T. D. Koepsell, M. Von Korff, R. A. Deyo, W. E. Barlow, and H. Checkoway, "Predicting long-term functional limitations among back pain patients in primary care settings," Journal of Clinical Epidemiology, vol. 50, no. 1, pp. 31-43, 1997.

[46] P. U. Dijkstra, C. P. van der Schans, and J. H. B. Geertzen, "Risk perception of developing complex regional pain syndrome I," Clinical Rehabilitation, vol. 17, no. 4, pp. 454-456, 2003.

[47] O. Guttmann and V. Wykes, "Images in clinical medicine. Complex regional pain syndrome type 1," The New England journal of medicine, vol. 359, no. 5, p. 508, 2008.

[48] A. Sarikaya, I. Sarikaya, G. Pekindil, M. F. Firat, and Y. Pekindil, "Technetium-99m sestamibi limb scintigraphy in post-traumatic reflex sympathetic dystrophy: preliminary results," European Journal of Nuclear Medicine, vol. 28, no. 10, pp. 1517-1522, 2001.

[49] M. Tondeur, A. Sand, and H. Ham, "Interobserver reproducibility in the interpretation of bone scans from patients suspected of having reflex sympathetic dystrophy," Clinical Nuclear Medicine, vol. 30, no. 1, pp. 4-10, 2005.

[50] J. Beltran and S. Shankman, "MR imaging of bone lesions of the ankle and foot," Magnetic Resonance Imaging Clinics of North America, vol. 9, no. 3, pp. 553-566, 2001.

[51] M. Schürmann, J. Zaspel, P. Löhr et al., "Imaging in early posttraumatic complex regional pain syndrome: a comparison of diagnostic methods," Clinical Journal of Pain, vol. 23, no. 5, pp. 449-457, 2007.

[52] B. M. Ingle, S. M. Hay, H. M. Bottjer, and R. Eastell, "Changes in bone mass and bone turnover following distal forearm fracture," Osteoporosis International, vol. 10, no. 5, pp. 399-407, 1999.

[53] M. Wertli, L. M. Bachmann, S. S. Weiner, and F. Brunner, "Prognostic factors in complex regional pain syndrome 1: a systematic review," Journal of Rehabilitation Medicine, vol. 45, no. 3, pp. 225-231, 2013.

[54] A. Zyluk, "The natural history of post-traumatic reflex sympathetic dystrophy," Journal of Hand Surgery: British Volume, vol. 23, no. 1, pp. 20-23, 1998.

[55] A. Zyluk and P. Puchalski, "Complex regional pain syndrome: observations on diagnosis, treatment and definition of a new subgroup," Journal of Hand Surgery: European Volume, vol. 38, no. 6, pp. 599-606, 2013.

[56] T. J. Hoover and J. A. Siefert, "Soft tissue complications of orthopedic emergencies," Emergency Medicine Clinics of North America, vol. 18, no. 1, pp. 115-139, 2000.
[57] R. S. G. M. Perez, P. E. T. Burm, W. W. A. Zuurmond et al., "Interrater reliability of diagnosing complex regional pain syndrome type I," Acta Anaesthesiologica Scandinavica, vol. 46, no. 4, pp. 447-450, 2002.

[58] D. A. Monti, C. L. Herring, R. J. Schwartzman, and M. Marchese, "Personality assessment of patients with complex regional pain syndrome type I," The Clinical Journal of Pain, vol. 14, no. 4, pp. 295-302, 1998.

[59] J. A. Lohnberg and E. M. Altmaier, "A review of psychosocial factors in complex regional pain syndrome," Journal of Clinical Psychology in Medical Settings, vol. 20, no. 2, pp. 247-254, 2013.

[60] D. A. W. M. van der Windt, T. Kuijpers, P. Jellema, G. J. M. G. van der Heijden, and L. M. Bouter, "Do psychological factors predict outcome in both low-back pain and shoulder pain?" Annals of the Rheumatic Diseases, vol. 66, no. 3, pp. 313-319, 2007.

[61] H. J. Pollack, R. Neumann, and E. Pollack, "Sudeck's disease and psyche," Beitrage zur Orthopadie und Traumatologie, vol. 27, no. 8, pp. 463-468, 1980.

[62] J. A. Hayden, P. Côté, and C. Bombardier, "Evaluation of the quality of prognosis studies in systematic reviews," Annals of Internal Medicine, vol. 144, no. 6, pp. 427-437, 2006.

[63] S. Sanderson, I. D. Tatt, and J. P. T. Higgins, “Tools for assessing quality and susceptibility to bias in observational studies in epidemiology: a systematic review and annotated bibliography," International Journal of Epidemiology, vol. 36, no. 3, pp. 666676, 2007.

[64] M. H. Feliu and C. L. Edwards, "Psychologic factors in the development of complex regional pain syndrome: history, myth, and evidence," Clinical Journal of Pain, vol. 26, no. 3, pp. 258263, 2010.

[65] M. de Mos, F. J. P. M. Huygen, J. P. Dieleman, J. S. H. A. Koopman, B. H. C. Stricker, and M. C. J. M. Sturkenboom, "Medical history and the onset of complex regional pain syndrome (CRPS)," Pain, vol. 139, no. 2, pp. 458-466, 2008.

[66] B. K. Grunert, C. A. Devine, J. R. Sanger, H. S. Matloub, and D. Green, "Thermal self-regulation for pain control in reflex sympathetic dystrophy syndrome," Journal of Hand Surgery, vol. 15, no. 4, pp. 615-618, 1990.

[67] D. J. Bean, M. H. Johnson, and R. R. Kydd, "The outcome of complex regional pain syndrome type 1: a systematic review," The Journal of Pain, vol. 15, no. 7, pp. 677-690, 2014.

[68] Z. Li, B. P. Smith, C. Tuohy, T. L. Smith, and L. Andrew Koman, "Complex regional pain syndrome after hand surgery," Hand Clinics, vol. 26, no. 2, pp. 281-289, 2010.

[69] R. H. Rho, R. P. Brewer, T. J. Lamer, and P. R. Wilson, "Complex regional pain syndrome," Mayo Clinic Proceedings, vol. 77, no. 2, pp. 174-180, 2002. 


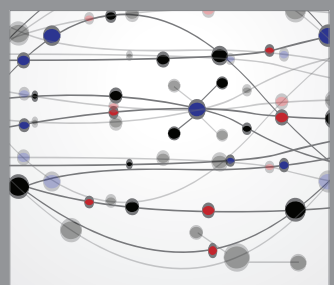

The Scientific World Journal
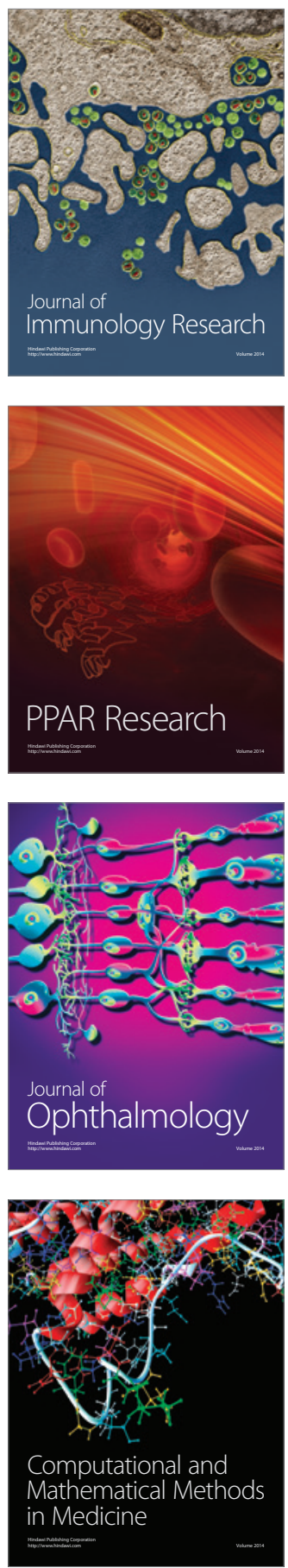

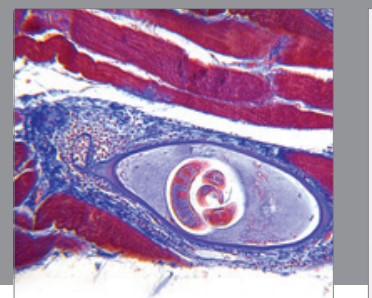

Gastroenterology

Research and Practice
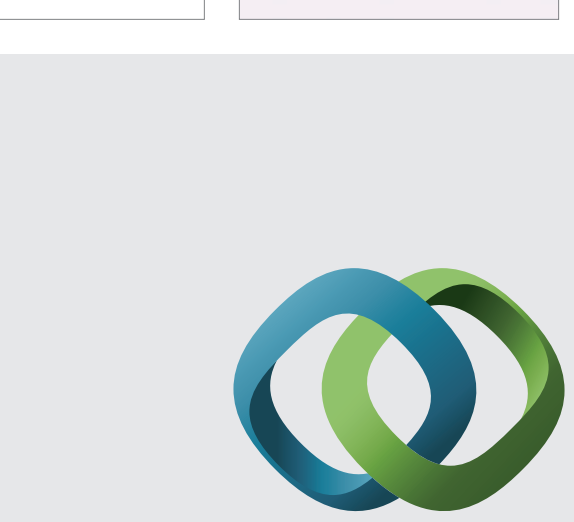

\section{Hindawi}

Submit your manuscripts at

http://www.hindawi.com
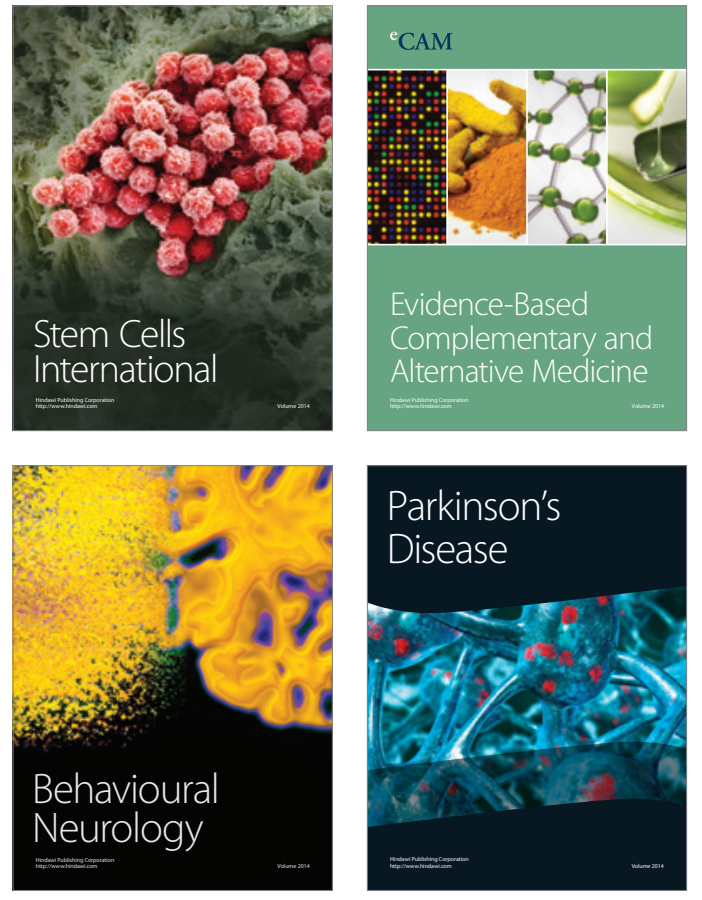
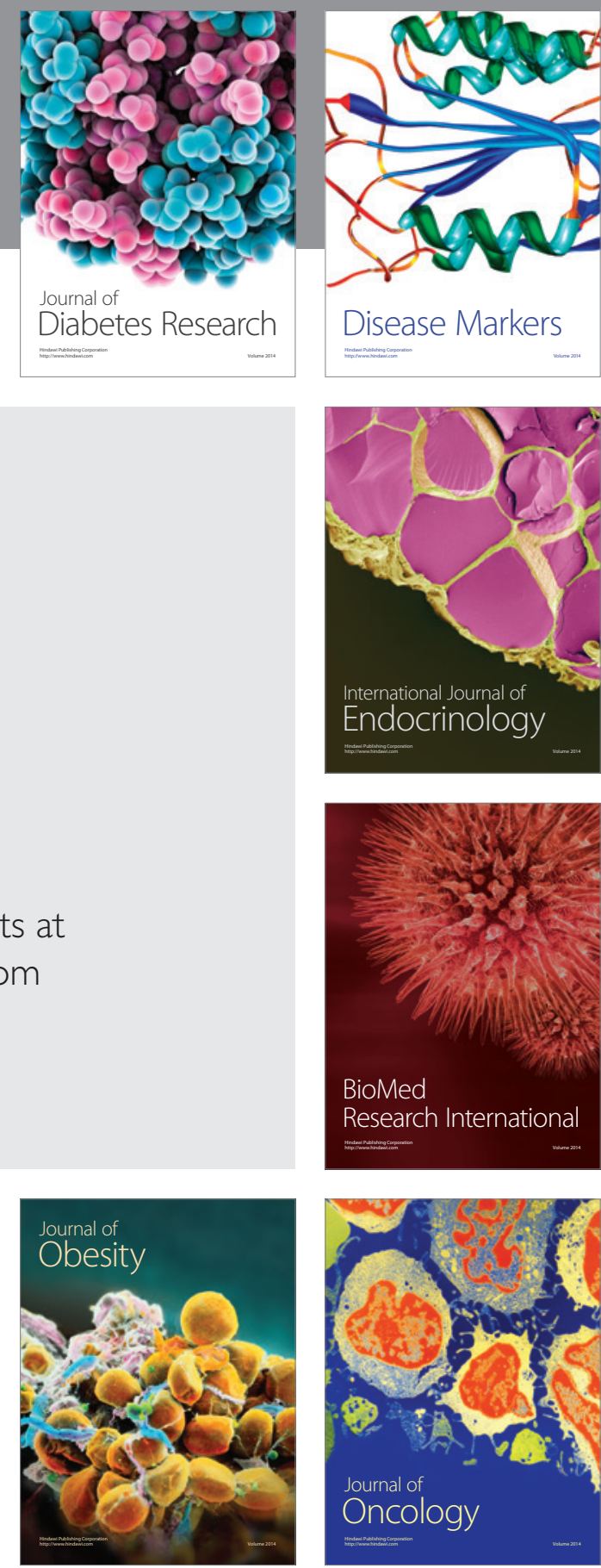

Disease Markers
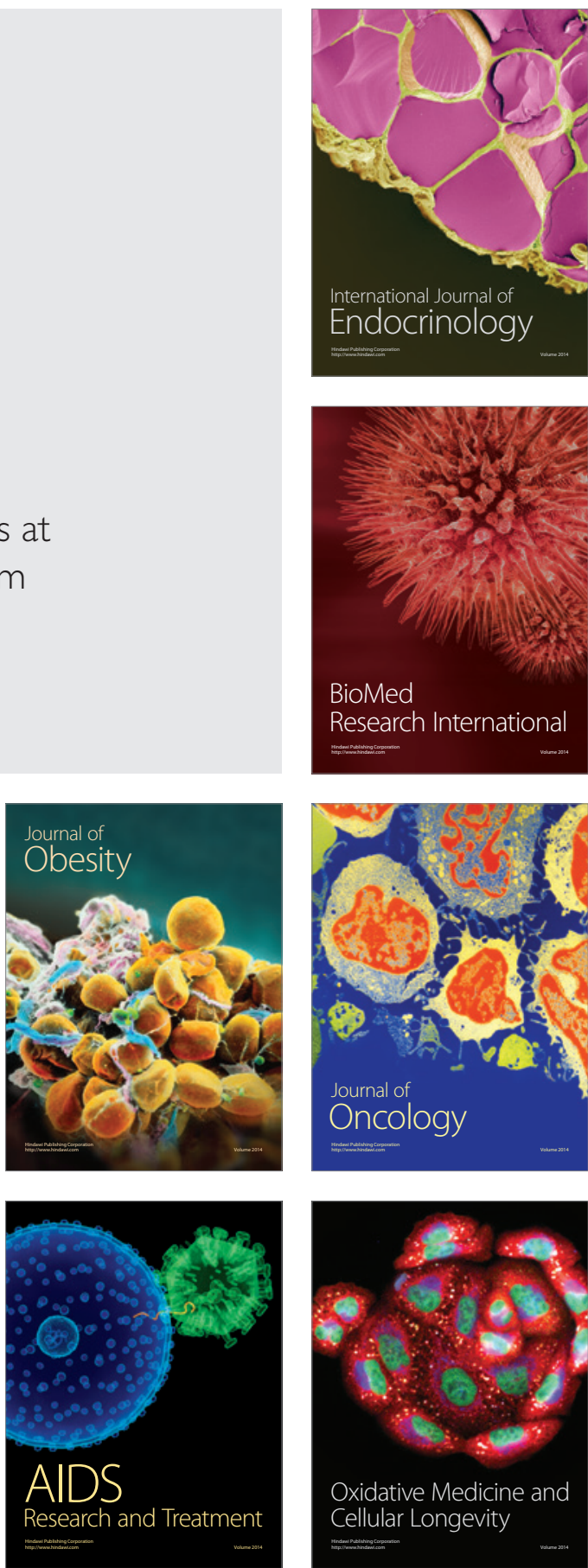